\title{
Helicobacter pylori Infection in Patients with Chronic Kidney Disease: A Systematic Review and Meta-Analysis
}

\author{
Suk Pyo Shin ${ }^{1}$, Chang Seok Bang ${ }^{1,2}$, Jae Jun Lee ${ }^{2,3}$, and Gwang Ho Baik ${ }^{1}$ \\ ${ }^{1}$ Department of Internal Medicine, ${ }^{2}$ Institute of New Frontier Research, and ${ }^{3}$ Department of Anesthesiology and Pain Medicine, Hallym \\ University College of Medicine, Chuncheon, Korea
}

Background/Aims: Insufficient systematic reviews were conducted in the previous meta-analyses about the prevalence of Helicobacter pylori infection in patients with chronic kidney disease (CKD). The aim of this study was to evaluate the prevalence of $H$. pylori infection in patients with CKD. Methods: A systematic review of studies that evaluated the prevalence of $H$. pylori infection in patients with CKD compared to a control group was performed. Only studies with adult patients were included, and studies with renal transplant recipients or diabetic nephropathy patients were excluded. Random-effects model meta-analyses with sensitivity analyses and subgroup analyses were conducted to confirm the robustness of the main result. A meta-regression analysis was conducted to explore the influence of potential heterogeneity on the outcomes. The methodological quality of the included publications was evaluated using the Risk of Bias Assessment tool for Nonrandomized Studies. Publication bias was also assessed. Results: In total, 47 studies were identified and analyzed. The total prevalence of $H$. pylori infection was $48.2 \%(1,968 / 4,084)$ in patients with CKD and $59.3 \%(4,097 / 6,908)$ in the control group. Pooled analysis showed a significantly lower prevalence of $H$. pylori infection in patients with CKD (vs control group: odds ratio, 0.64; $95 \%$ confidence interval, 0.52 to 0.79 ). Sensitivity analyses revealed consistent results, and meta-regression analysis showed no significant confounders. No publication bias was detected. Conclusions: The results of this study suggest a lower prevalence of $H$. pylori infection in patients with CKD. (Gut Liver 2019;13:628-641)

Key Words: Helicobacter pylori; Meta-analysis; Chronic kidney disease

\section{INTRODUCTION}

Helicobacter pylori is the most common chronic bacterial infection in humans and is related to various gastrointestinal diseases such as gastritis, peptic ulcer, gastric cancer, and extranodal marginal zone lymphoma of mucosa-associated lymphoid tissue. $^{1,2}$ The extraintestinal linking of $H$. pylori to various conditions, including hematologic, cardiovascular, metabolic, neurologic, and dermatologic disorders, has been investigated and recently published; the Maastricht V/Florence Consensus Report recommends eradication for patients who have iron deficiency anemia, idiopathic thrombocytopenic purpura, and vitamin B12 deficiency, although it is a weak grade recommendation. ${ }^{3-5}$

Patients with chronic kidney disease (CKD) often complain of dyspepsia due to various causes, and $H$. pylori infection should now be excluded for the diagnosis of functional dyspepsia. ${ }^{3}$ However, epidemiologic studies have shown inconsistent results about the association between $H$. pylori infection and CKD., The increased interest in the relationship between $H$. pylori infection and CKD is due to extraintestinal associations such as insulin resistance or metabolic syndrome associated with $H$. pylori infection, which is expected to be highly relevant because diabetes and hypertension are the most common causes of CKD. ${ }^{5,8}$

Three meta-analyses have been conducted for the association of $H$. pylori infection and CKD. ${ }^{6,79}$ Wijarnpreecha et al. ${ }^{7}$ found no significant association between non-dialysis-dependent CKD and $H$. pylori infection. Gu et al. ${ }^{6}$ also revealed no evidence of association between dialysis-dependent CKD and $H$. pylori infection. Although these studies commonly claim no association, many articles were omitted during the literature search, and since both meta-analyses included only a subgroup (Wijarnpreecha et al. only included non-dialysis-dependent CKD, and

Correspondence to: Chang Seok Bang

Department of Internal Medicine, Hallym University College of Medicine, 77 Sakju-ro, Chuncheon 24253, Korea

Tel: +82-33-240-5821, Fax: +82-33-241-8064, E-mail: csbang@hallym.ac.kr

Received on November 24, 2018. Revised on December 11, 2018. Accepted on May 27, 2018. Published online May $27,2019$. pISSN 1976-2283 eISSN 2005-1212 https://doi.org/10.5009/gnl18517

(a) This is an Open Access article distributed under the terms of the Creative Commons Attribution Non-Commercial License (http://creativecommons.org/licenses/by-nc/4.0) which permits unrestricted non-commercial use, distribution, and reproduction in any medium, provided the original work is properly cited. 
$\mathrm{Gu}$ et al. only included dialysis-dependent CKD), an integrated analysis and subsequent sensitivity and subgroup analyses confirming the main result are needed. Another meta-analysis by Wijarnpreecha et al. ${ }^{9}$ found no association between endstage renal disease (ESRD) and H. pylori infection. However, this meta-analysis included several studies with pediatric patients and also many articles were omitted during the literature search. Moreover, the method of dialysis (hemodialysis or peritoneal dialysis), ethnicity of the enrolled population, and methodological quality of the included studies were not considered as confounding factors in the previous meta-analyses (Table 1). Therefore, this study aimed to evaluate the prevalence of $H$. pylori infection in patients with CKD with systematic review, metaanalysis, and meta-regression.

\section{MATERIALS AND METHODS}

This systematic review and meta-analysis fully adhered to the principles of the Preferred Reporting Items for Systematic Reviews and Meta-Analyses (PRISMA) checklist (Supplementary Table 1). ${ }^{10}$

\section{Literature searching strategy}

MEDLINE (through PubMed), the Cochrane library, and Em- base were searched using common keywords associated with H. pylori infection or CKD (from inception to April 2018) by two independent evaluators (C.S.B. and S.P.S.). Medical Subject Heading (MeSH) or Emtree keywords were selected for searching electronic databases. The abstracts of all identified studies were reviewed to exclude irrelevant articles. Full-text reviews were performed to determine whether the inclusion criteria were satisfied in the remaining studies, and the bibliographies of relevant articles were rigorously reviewed to identify additional studies. Disagreements between the evaluators were resolved by discussion. The detailed searching strategy is described in Supplementary Table 2.

\section{Selection criteria}

We included studies that met the following criteria: (1) studies designed to evaluate the prevalence of $H$. pylori infection in patients with CKD (vs. a control group without kidney diseases); (2) studies of human subjects; and (3) full-text publications. Studies that met the all of the inclusion criteria were sought and selected. The exclusion criteria were as follows: (1) publications with incomplete data; (2) review articles; (3) pediatric studies; (4) letters or case articles; (5) abstract-only publications; and (6) studies with CKD including DM nephropathy or renal transplant recipient (meta-analysis with DM nephropathy or renal trans-

Table 1. Comparison of Previous Meta-Analyses with the Current Analysis

\begin{tabular}{|c|c|c|c|c|}
\hline Parameters & Current study & Gu et $a l^{6}$ & Wijarnpreecha et al. ${ }^{7}$ & Wijarnpreecha et al. ${ }^{9}$ \\
\hline No. of included studies & $\begin{array}{l}47 \text { Studies in systematic } \\
\text { review (46 studies for } \\
\text { meta-analysis) }\end{array}$ & 15 Studies & 9 Studies & $\begin{array}{l}37 \text { Studies in systematic } \\
\text { review (35 studies for } \\
\text { meta-analysis) }\end{array}$ \\
\hline Main outcome & $\begin{array}{l}\text { Lower prevalence of } \\
\text { H. pylori infection in } \\
\text { patients with CKD } \\
\text { compared to control group } \\
\text { (OR, 0.64; 95\% } \\
\text { CI, 0.52-0.79) }\end{array}$ & $\begin{array}{l}\text { No significant difference } \\
\text { in the prevalence of } H \text {. } \\
\text { pylori infection between } \\
\text { patients with dialysis and } \\
\text { control group (OR, 0.86; } \\
95 \% \text { CI, 0.52-1.42) }\end{array}$ & $\begin{array}{l}\text { No significant difference } \\
\text { in the prevalence of } H \text {. } \\
\text { pylori infection between } \\
\text { patients with CKD and } \\
\text { control group (OR, 1.2; } \\
\text { 95\% CI, 0.73-1.97) }\end{array}$ & $\begin{array}{l}\text { No significant difference in } \\
\text { the prevalence of } H \text {. pylori } \\
\text { infection between patients } \\
\text { with ESRD and control } \\
\text { group (RR, 0.77; 95\% CI, } \\
\text { 0.59-1.00) }\end{array}$ \\
\hline $\begin{array}{l}\text { Whether dialysis } \\
\text { patients were } \\
\text { included or not }\end{array}$ & $\begin{array}{l}\text { Included dialysis patients } \\
\text { (ESRD) and non-dialysis } \\
\text { patients with CKD }\end{array}$ & $\begin{array}{l}\text { Only patients with dialysis- } \\
\text { dependent CKD (ESRD) }\end{array}$ & $\begin{array}{l}\text { Only patients with non- } \\
\text { dialysis-dependent CKD }\end{array}$ & Only patients with ESRD \\
\hline $\begin{array}{l}\text { Whether pediatric patients } \\
\text { were included or not }\end{array}$ & Excluded & Included & Excluded & Included \\
\hline $\begin{array}{l}\text { Whether diabetic } \\
\text { nephropathy or renal } \\
\text { transplant recipient were } \\
\text { included or not }\end{array}$ & Excluded & Included & Included & Included \\
\hline $\begin{array}{l}\text { Whether analysis based on } \\
\text { modifiers were included } \\
\text { or not (meta-regression) }\end{array}$ & Included & Not included & Not included & Not included \\
\hline
\end{tabular}

H. pylori, Helicobacter pylori; CKD, chronic kidney disease; OR, odds ratio; CI, confidence interval; ESRD, end-stage renal disease; RR, risk ratio. 
plant recipient is different topic of interest and already published ${ }^{11,12}$ ). Studies meeting at least one of the exclusion criteria were excluded from this analysis.

\section{Methodological quality}

The methodological quality of the included publications was assessed using the Risk of Bias Assessment tool for Nonrandomized Studies (RoBANS). ${ }^{13}$ The RoBANS tool contains six domains, including the selection of participants, confounding variables, measurement of intervention (exposure), blinding of outcome assessment, incomplete outcome data, and selective outcome reporting. ${ }^{13}$ RoBANS is a validated tool that is reliable and feasible for the assessment of the methodological quality of nonrandomized studies. Review Manager version 5.3.3 (RevMan for Windows 7; the Nordic Cochrane Centre, Copenhagen, Denmark) was used to generate the summary of RoBANS results. Studies with matched participants (e.g., age or sex) and the diagnosis of $H$. pylori infection with two or more methods were ranked with low risk of bias in the selection of participants and incomplete outcome date variable, respectively. Two of the evaluators (C.S.B. and S.P.S.) independently assessed the methodological quality of all included studies, and any disagreements between the evaluators were resolved by discussion or consultation with a third evaluator (G.H.B.).

\section{Primary and modifier-based analysis}

Two evaluators (C.S.B. and S.P.S.) independently used the same data fill-in form to collect the primary summary outcome and modifiers in each study. The outcome was the prevalence of H. pylori infection in patients with CKD and the control groups. These ratios were extracted and evaluated using odds ratios (ORs). Sensitivity analyses, including cumulative and one-studyremoved analyses, were performed to confirm the robustness of the main analysis results. These analyses were calculated in the order of publication year or effect size to find whether the time trend exists or which study is more or less influential in the pooled estimate and to find the small-study effect (to ensure no changes in the effect size if more small-effect size studies were added). We also performed subgroup and meta-regression analyses to identify the source of heterogeneity based on the multiple modifiers identified during the systematic review. These modifiers include the ethnicity of the study population, classification of CKD (ESRD on dialysis vs CKD not on dialysis), dialysis method among ESRD population (hemodialysis or not), duration of dialysis (more than 4 years or not) and methodological quality.

\section{Statistical analysis}

Comprehensive Meta-Analysis software version 3 (Borenstein M, Hedges L, Higgins J and Rothstein H; Biostat, Englewood, NJ, USA) was used for this meta-analysis. We calculated the ORs with 95\% confidence intervals (CIs) using $2 \times 2$ tables from the original articles to compare the prevalence of $H$. pylori infection between the patients with CKD and the control group whenever possible. Heterogeneity was determined using the $\mathrm{I}^{2}$ test developed by Higgins, which measures the percentage of total variation across studies. ${ }^{14} \mathrm{I}^{2}$ was calculated as follows: $\mathrm{I}^{2}$ $(\%)=100 \times(Q-d f) / Q$, where $Q$ is Cochrane's heterogeneity statistic and df signifies the degrees of freedom. Negative values for $\mathrm{I}^{2}$ were set to zero, and an $\mathrm{I}^{2}$ value over 50\% was considered to be of substantial heterogeneity (range, $0 \%$ to $100 \%$ ). ${ }^{15}$ Pooledeffect sizes with 95\% CIs were calculated using a random effects model and the method of DerSimonian and Laird due to methodological heterogeneity. ${ }^{16}$ These results were confirmed by the $\mathrm{I}^{2}$ test. Significance was set at $\mathrm{p}=0.05$. Publication bias was evaluated using Begg's funnel plot, Egger's test of the intercept, Begg and Mazumdar's rank correlation test, and Duval and Tweedie's trim and fill method. ${ }^{17-21}$

\section{RESULTS}

\section{Identification of relevant studies}

Fig. 1 presents a flow diagram showing how relevant studies were identified. In total, 1,296 articles were identified by a search of three databases. In all, 347 were duplicate studies, and an additional 732 studies were excluded during the initial screening through a review of titles and abstracts. The full texts of the remaining 219 studies were then thoroughly reviewed. Among these studies, 171 articles were excluded from the final analysis. The reasons for study exclusion during the final review were as follows: narrative review article $(n=7)$, meta-analysis or systematic review $(n=5)$, letters, comment, editorial or reply to questions $(n=15)$, abstract-only article $(n=4)$, case study $(n=5)$, duplicated data $(n=1)$, and incomplete data $(n=134)$. Forty-eight studies ${ }^{22-69}$ were included in the systematic review; however, study by Kong et al. ${ }^{40}$ showed no crude rate of $H$. pylori infection, therefore, this was excluded in the final meta-analysis. The remaining 47 studies ${ }^{22-39,41-69}$ were included in the final quantitative analysis.

\section{Characteristics of included studies}

In the 47 case-control or cross-sectional studies, we identified a total of 4,084 patients with CKD (2,470 patients on dialysis and 1,916 patients on hemodialysis) and 6,908 controls without CKD. The total prevalence of $H$. pylori infection in patients with CKD was 48.2\% $(1,968 / 4,084)$, and it was 59.3\% $(4,097 / 6,908)$ in the control group. The included studies were published between 1989 and 2017. Only one study included an African population, ${ }^{22}$ whereas the remaining studies included Asian (17 studies), ${ }^{23-39}$ Western (16 studies), ${ }^{41-56}$ Middle Eastern (11 studies), ${ }^{57-67}$ and South American populations (two studies). ${ }^{68,69}$ Most articles were written in English, except for two Spanish, ${ }^{68,69}$ one Japanese, ${ }^{23}$ one Korean, ${ }^{27}$ one $\mathrm{Czech}^{51}$ and one Turkish ${ }^{59}$ studies. The age of the enrolled population ranged from $32.5 \pm 5.3$ 


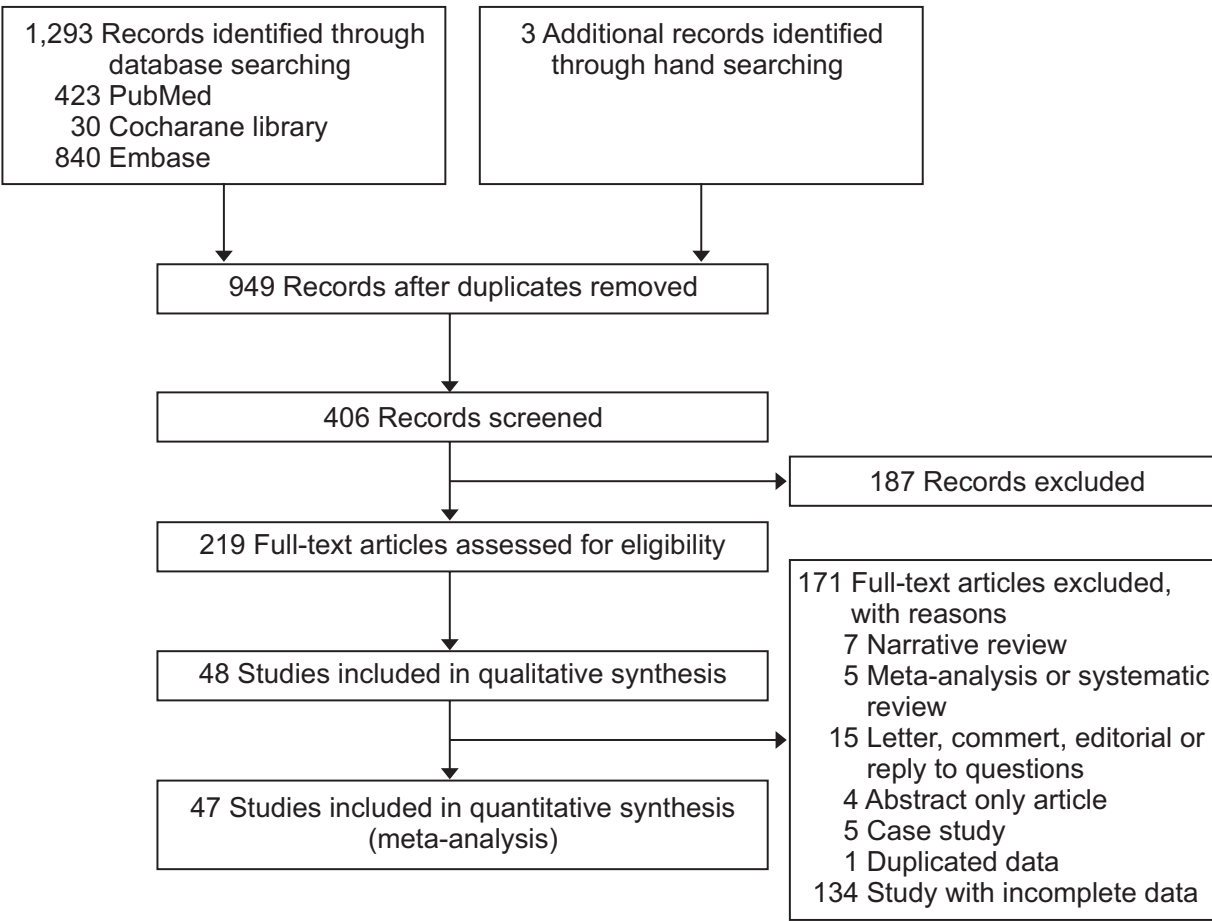

Fig. 1. Flow diagram for identification of relevant studies. to $69.5 \pm 13.8$ years (mean \pm standard deviation). The diagnostic method of $H$. pylori infection varied according to each study, and included histology (Warthin-Starry, H\&E, Giemsa, alcian blue-periodic acid Schiff's, Loeffler's methylene blue stain), culture, serology (IgG antibody against $H$. pylori), urease testing, phase-contrast microscopy, analysis for the stool antigen for $H$. pylori, and a urea breath test. The duration of dialysis in the enrolled population ranged from at least 6 months to $8.4 \pm 0.3$ years (mean \pm standard deviation). Most studies presented a crude rate of $H$. pylori infection in patients with CKD versus a control group, and two studies ${ }^{37,40}$ presented adjusted ORs, which were adjusted for age, sex, peptic ulcer history, steroid or medication use, diabetes, hypertension, chronic heart failure, coronary artery disease, and liver cirrhosis in Chang and $\mathrm{Hu}^{37}$ and for sex, age, hypertension, diabetes, body mass index, uric acid, smoking, drinking, total cholesterol, triglycerides, low-density lipoprotein cholesterol, and high-density lipoprotein cholesterol in Kong et al. ${ }^{40}$ The clinical characteristics of the included studies are shown in Table 2 (study by Kong et al. is described in the Table 2, but was not included in the final meta-analysis).

\section{Prevalence of $\boldsymbol{H}$. pylori infection in patients with CKD}

The pooled meta-analysis of 34 studies exhibited a significantly lower prevalence of $H$. pylori infection in patients with CKD (vs a control group) (OR, 0.64; 95\% CI, 0.52 to 0.79 ; $\mathrm{I}^{2}=79.53 \%$ ) in a random effect model analysis (Fig. 2).

\section{Sensitivity meta-analysis}

A cumulative meta-analysis of the included studies based on publication year showed no specific trend over time (Supple- mentary Fig. 1A). A cumulative meta-analysis based on effect size showed no small study bias (Supplementary Fig. 1B). A one-study-removed meta-analysis revealed a stable feature (Supplementary Fig. 1C). Overall, the sensitivity meta-analyses revealed robust results.

\section{Subgroup analyses according to the modifiers}

The ESRD on dialysis subgroup showed robust lower prevalence of $H$. pylori (vs a control group) (OR, 0.58; 95\% CI, 0.51 to 0.66) (Supplementary Fig. 2A). The hemodialysis subgroup also showed lower prevalence of $H$. pylori (OR, 0.60; 95\% CI, 0.52 to 0.69) (Supplementary Fig. 2B). This effect was intensified in a subgroup of hemodialysis for more than 4 years (OR, 0.34; 95\% CI, 0.27 to 0.43) (Supplementary Fig. 2C).

However, analysis of the ethnicity of the enrolled population showed a different result. Asian (OR, 0.46; 95\% CI, 0.41 to 0.52) and Western population (OR, 0.78; 95\% CI, 0.66 to 0.92) showed a lower prevalence; the African (OR, 0.90; 95\% CI, 0.48 to 1.70), Middle Eastern (OR, 1.1; 95\% CI, 0.87 to 1.34 ), and South American populations (OR, 0.76; 95\% CI, 0.46 to 1.27) showed no significant difference of $H$. pylori infection in patients with CKD (vs a control group) (Supplementary Fig. 2D).

In terms of the methodological quality of the included studies, high-quality studies (defined as having no negative component in the RoBANS evaluation) showed a significantly lower prevalence of $H$. pylori infection in patients with CKD (OR, 0.57; 95\% CI, 0.49 to 0.67 ). However, low-quality studies (defined as having any negative component in the RoBANS evaluation) showed no significant difference (OR, 0.66; 95\% CI, 0.59 to 0.73) (Supplementary Fig. 2E). The detailed quality evaluation is described in Fig. 3. 


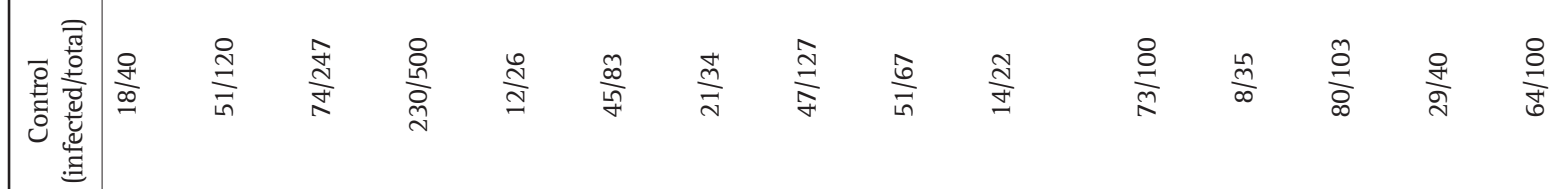

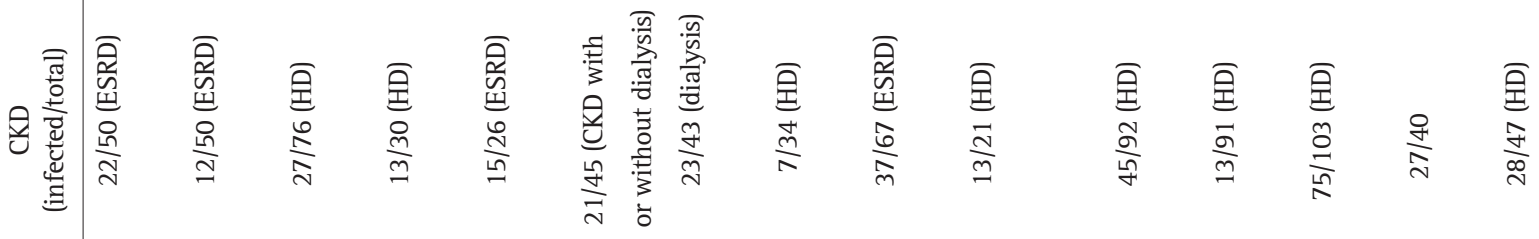

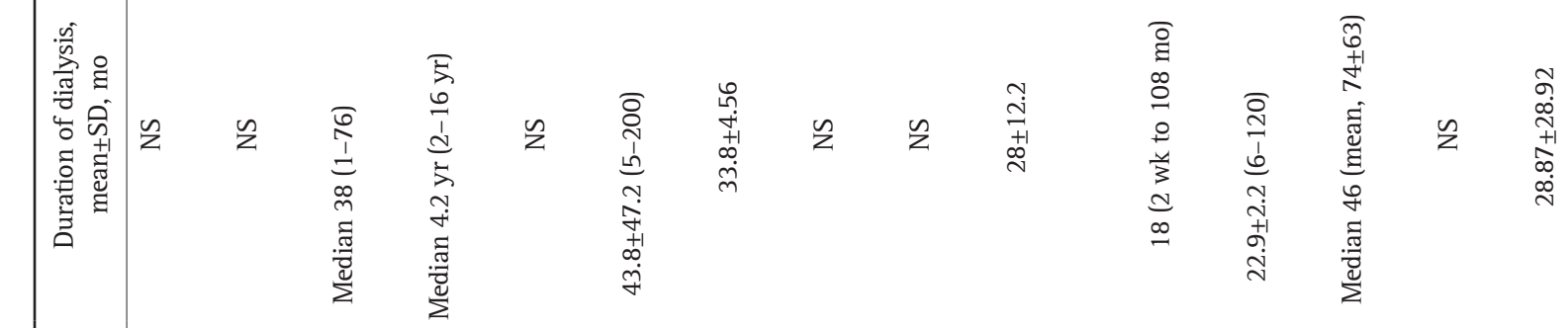
(II) 


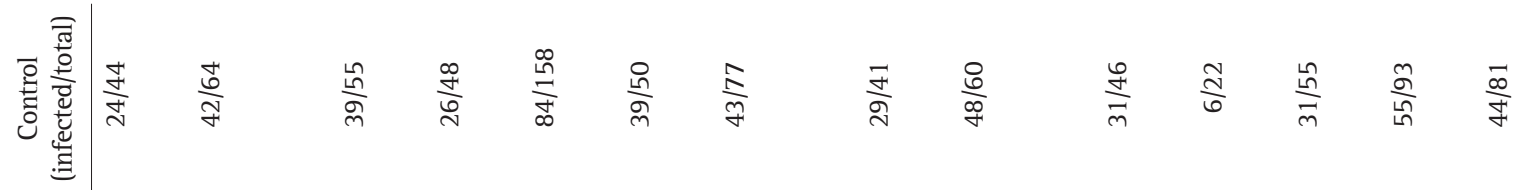

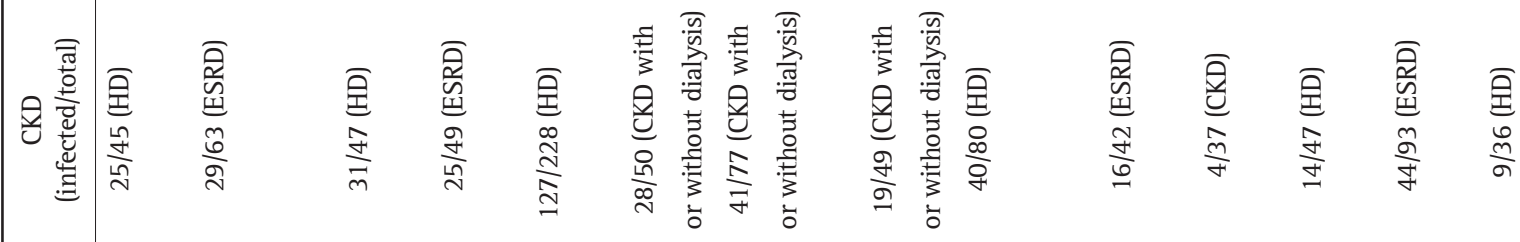

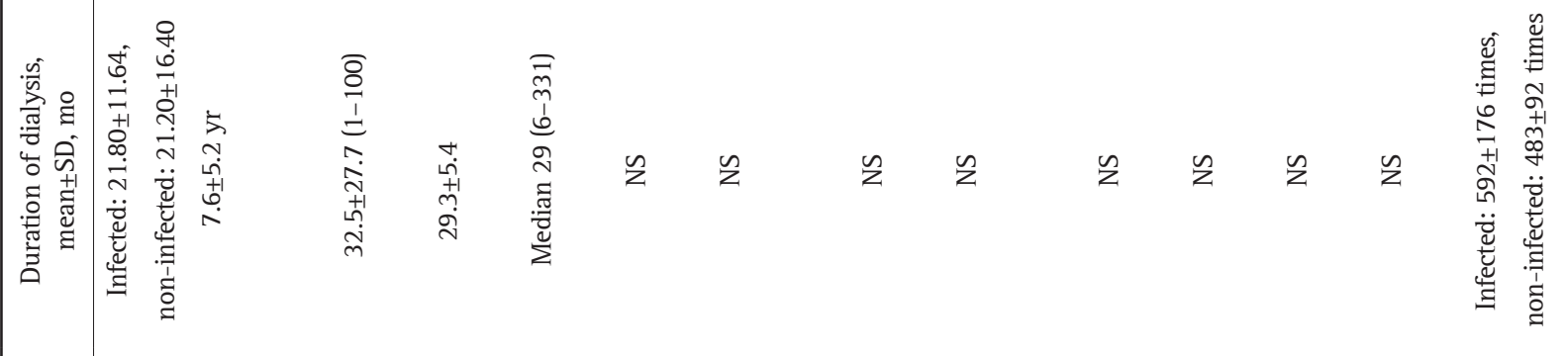

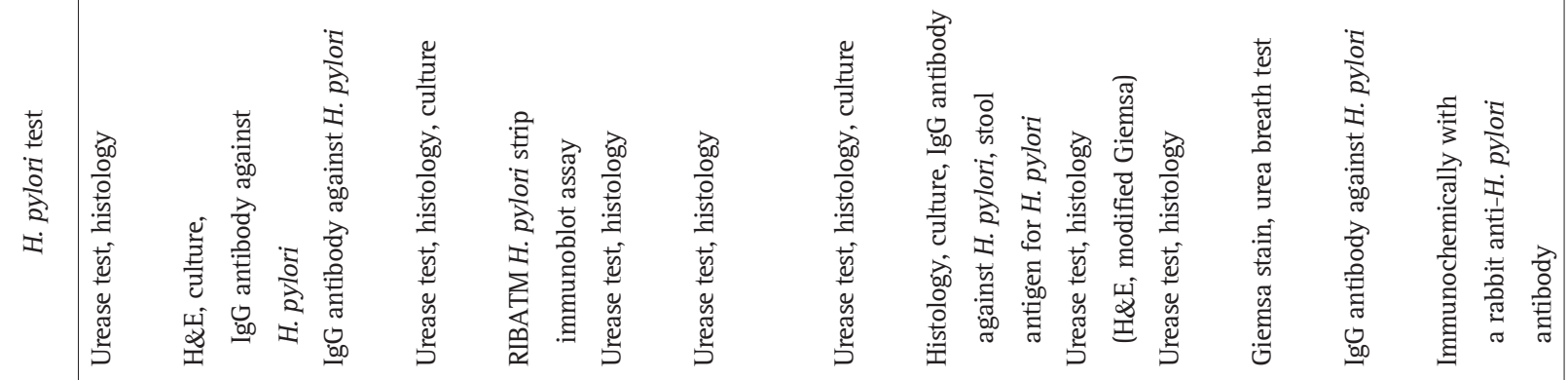

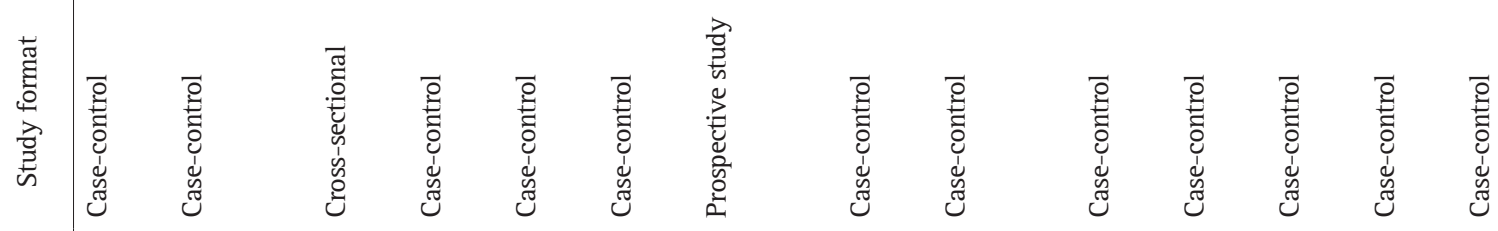

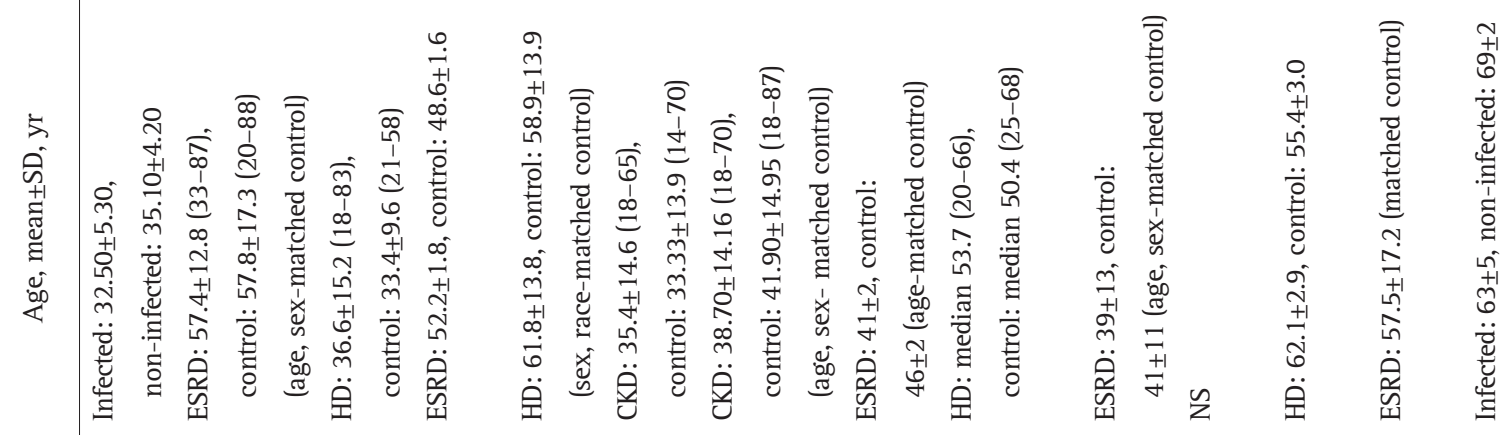

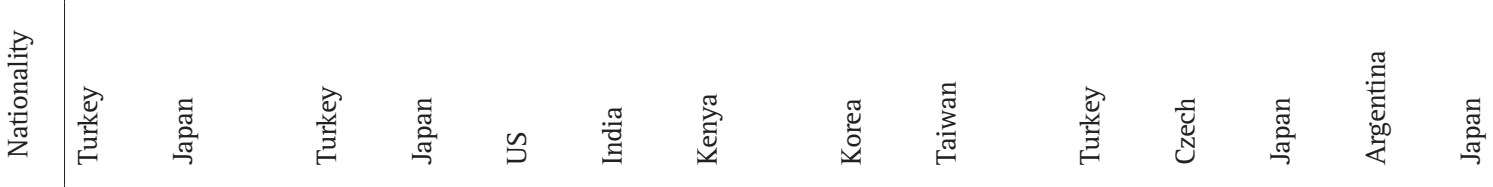

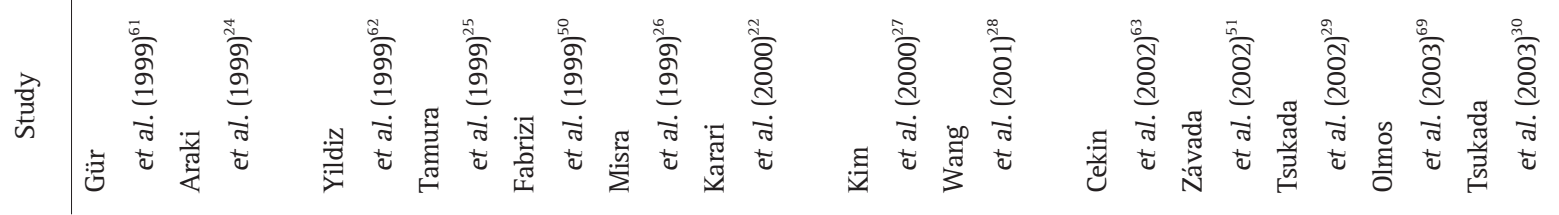




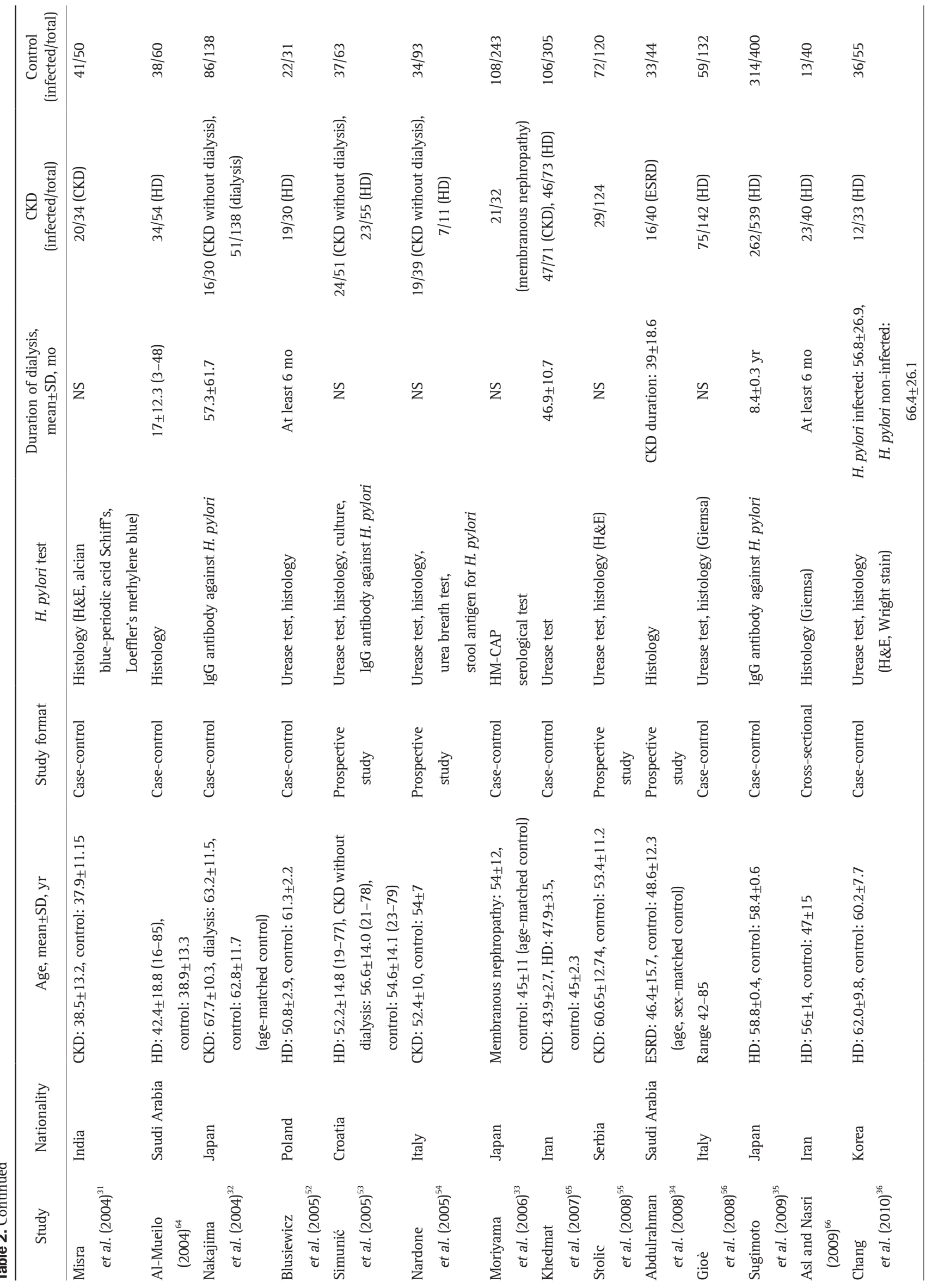


Shin SP, et al: Helicobacter pylori in Chronic Kidney Disease 635

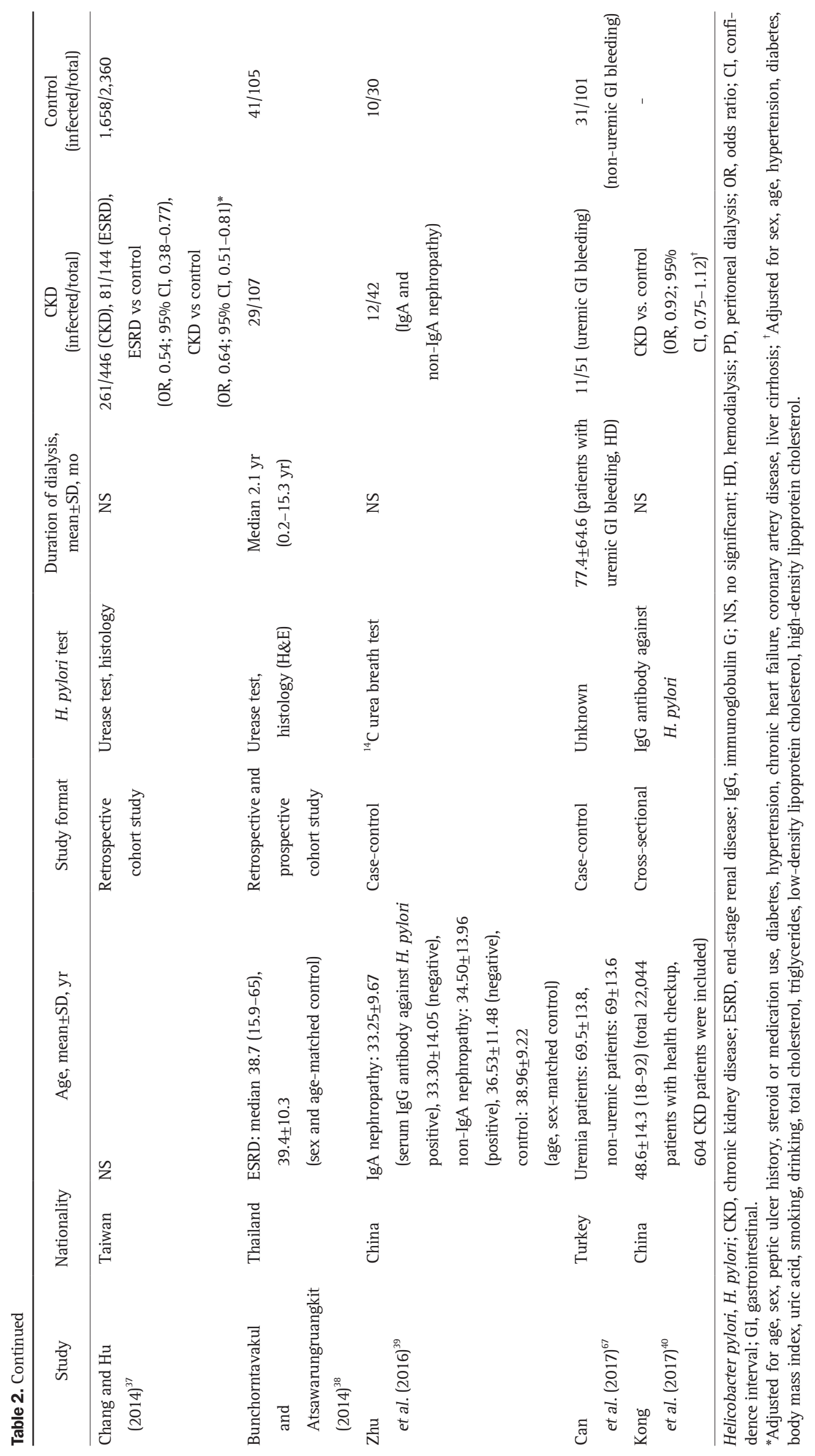




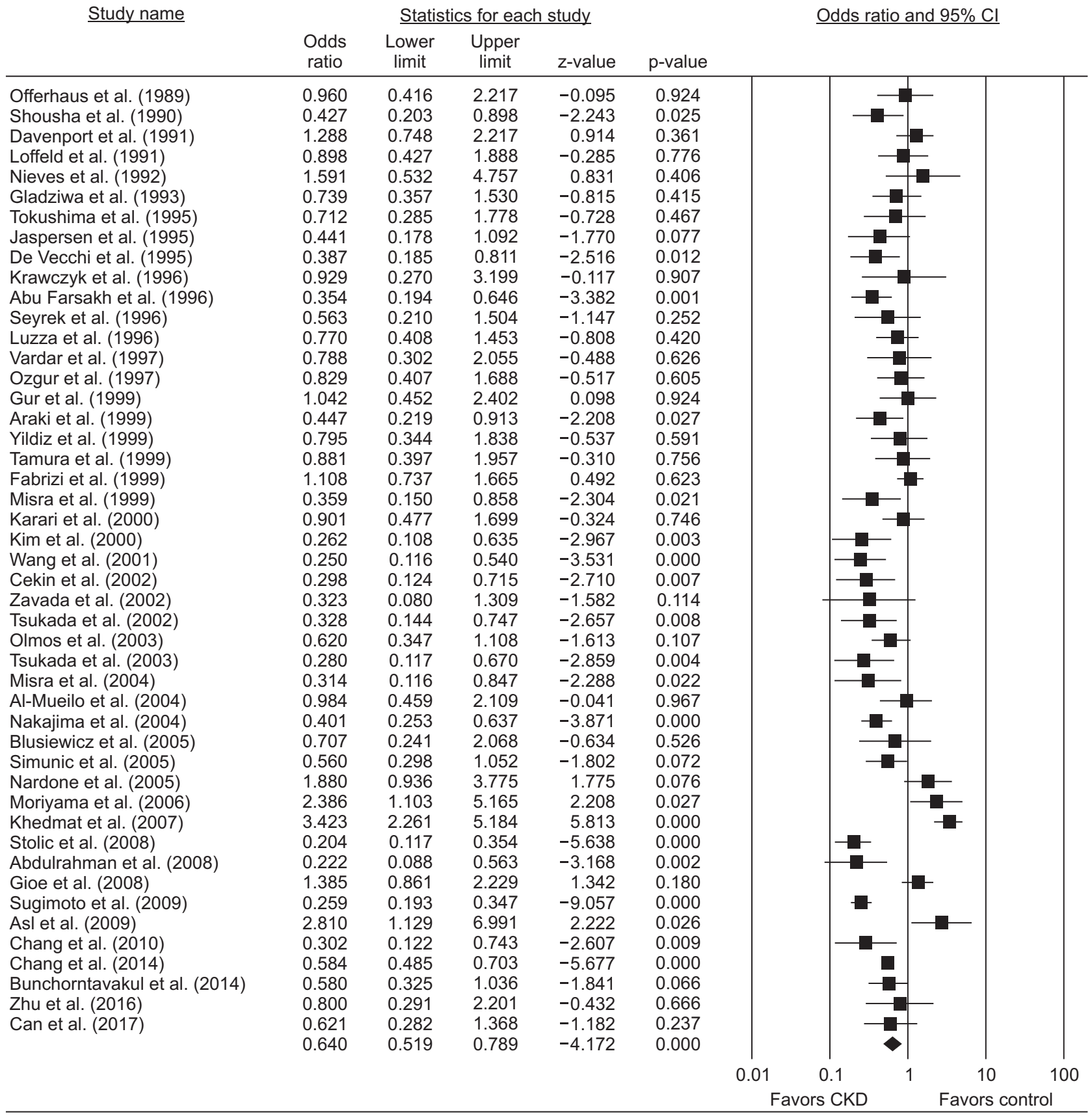

Fig. 2. Prevalence of Helicobacter pylori infection in patients with CKD (vs control group). The size of each square is proportional to the study's weight. Diamond is the summary estimate from the pooled studies (random-effects model). Heterogeneity: $\chi^{2}=224.693, \mathrm{df}=46$ ( $\mathrm{p}<0.001$ ), $\mathrm{I}^{2}=79.582 \%$. Test for overall effect: $\mathrm{Z}=-4.172(\mathrm{p}<0.001)$.

CKD, chronic kidney disease; CI, confidence interval.

\section{Meta-regression analyses}

Among the potential confounding factors, including whether the population was on dialysis or not, ethnicity, dialysis method, dialysis duration (more than 4 years), and methodological quality, there were no covariates that explained heterogeneity in the meta-regression tests (Table 3).

\section{Analysis of publication bias}

A funnel plot for the included studies is illustrated in Fig. 4 and shows a symmetrical shape. Egger's regression test revealed that the intercept was 0.23 (95\% CI, -1.23 to 1.68 ; t-value, 0.31 ; $\mathrm{df}=45, \mathrm{p}=0.38$ [1-tailed] and $\mathrm{p}=0.76$ [2-tailed]). A trim and fill analysis showed that no study was missed or trimmed. The rank correlation test showed Kendall's tau was -0.04 with a continuity correction ( $\mathrm{p}=0.33$ [1-tailed] and $\mathrm{p}=0.66$ [2-tailed]). Overall, 


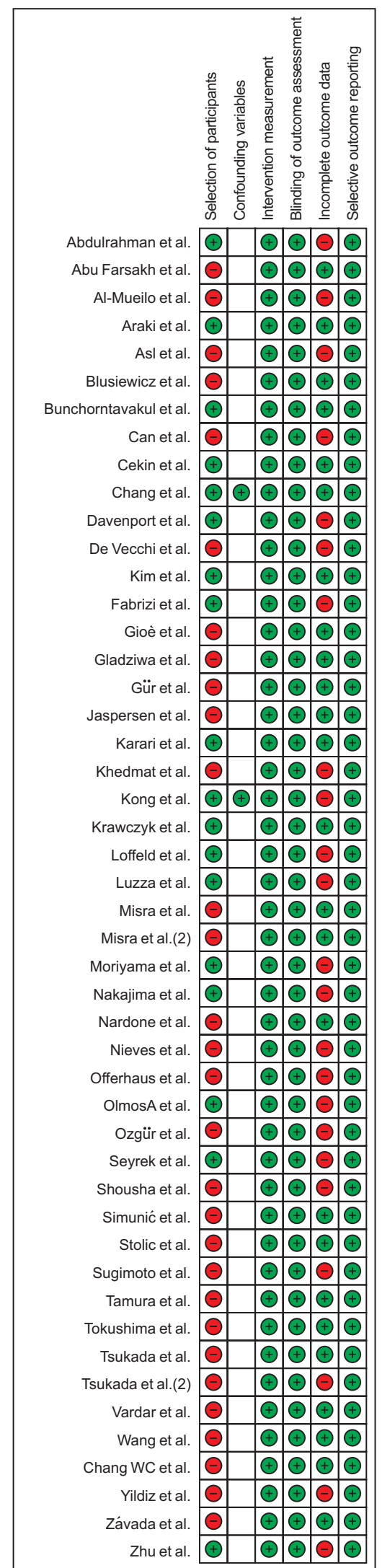

Fig. 3. Risk of Bias Assessment tool for Nonrandomized Studies (RoBANS) for the assessment of methodological quality for all included studies. (+) Denotes low risk of bias, blank denotes unclear risk of bias, (-) denotes high risk of bias. there was no evidence of publication bias in this meta-analysis.

\section{DISCUSSION}

This meta-analysis confirmed the lower prevalence of $H$. pylori infection in patients with CKD (The total prevalence of $H$. pylori infection was $48.2 \%$ in patients with CKD vs 59.3\% in the control group). Although the previous three meta-analyses claimed no significant association, the current study is the first meta-analysis representing the real prevalence because many articles were omitted during systematic review process in the previous systematic review (47 studies were included in the current study, whereas Wijarnpreecha et al. ${ }^{7}$ included nine studies, Gu et al. ${ }^{6}$ included 15 studies, and Wijarnpreecha et al. ${ }^{9}$ included 37 studies), and these studies enrolled a subgroup of patients with CKD according to whether patients were on dialysis or not. Many articles were omitted in these systematic reviews because searching strategy was unclear. ${ }^{6,79}$ Studies with renal transplant recipients or diabetic nephropathy, and pediatric population was included in the meta-analysis because inclusion criteria was vague (Table 1$)^{9}{ }^{9}$

Although most subgroup analyses verified according to the modifiers in the current study showed consistent results with main outcome, the ethnicity of the study population showed inconsistent results. Analyses with an Asian and Western population showed a significant lower prevalence and analyses of African, Middle Eastern, and South American populations commonly showed no significant difference. Considering most studies with an African, Middle Eastern, and South American population were included in the low-quality methodology group, these inconsistencies indicate and favor a significant lower prevalence of $H$. pylori infection in patients with CKD.

The most important factor for the determination of the methodological quality was an incomplete outcome of each study, especially the method of diagnosing $H$. pylori infection (Fig. 3). Included studies used various methods, including a urease test, histology, culture, a urea breath test, serology, or a stool antigen test. Although the urease test, histology, urea breath test, and stool antigen test have a high diagnostic value, with sensitivity and specificity exceeding 90\% for the determination of $H$. pylori infection status, each diagnostic method has some considerations. ${ }^{3,70,71}$ False-negative results in the urease test, histology, urea breath test, and stool antigen test can be detected when patients are taking antibiotics, proton pump inhibitors, or bismuth, which are frequently prescribed drugs in patients with $\mathrm{CKD},{ }^{3,71,72}$ Therefore, the Maastricht V/Florence Consensus Report recommends that proton pump inhibitors should be discontinued at least 2 weeks before testing, and antibiotics and bismuth should be discontinued at least 4 weeks before testing. ${ }^{3}$ The serology test, which detects an IgG antibody against $H$. pylori, needs local validation before clinical application, and its overall sensitivity and specificity from published studies was less than 90\%, 
Table 3. Results of Meta-Regression Analyses

\begin{tabular}{|c|c|c|c|c|}
\hline Model & Modifier & Coefficient & Standard error & $\mathrm{p}$-value \\
\hline \multirow[t]{10}{*}{ Model 1} & ESRD on dialysis vs CKD & -0.35 & 0.49 & 0.48 \\
\hline & Ethnicity & Asian: -0.62 & 0.76 & 0.41 \\
\hline & & Middle Eastern: 0.10 & 0.80 & 0.90 \\
\hline & & South American: 0.23 & 0.99 & 0.82 \\
\hline & & Western: -0.14 & 0.79 & 0.86 \\
\hline & & & & 0.09 (Q: 8.00, df: 4) \\
\hline & HD or not & HD: 0.06 & 0.34 & 0.86 \\
\hline & & No HD: -0.01 & 0.47 & 0.98 \\
\hline & & & & 0.98 (Q: 0.04, df: 2) \\
\hline & Methodological quality & 0.11 & 0.34 & 0.74 \\
\hline \multirow{9}{*}{ Model 2} & Ethnicity & Asian: -0.52 & 0.69 & 0.45 \\
\hline & & Middle Eastern: 0.19 & 0.71 & 0.79 \\
\hline & & South American: 0.34 & 0.89 & 0.70 \\
\hline & & Western: -0.04 & 0.70 & 0.95 \\
\hline & & & & 0.10 (Q: 7.76, df: 4) \\
\hline & HD or not & HD: 0.12 & 0.31 & 0.71 \\
\hline & & No HD: -0.001 & 0.45 & 0.99 \\
\hline & & & & 0.93 (Q: 0.14, df: 2) \\
\hline & Dialysis more than 4 years & -0.17 & 0.34 & 0.63 \\
\hline \multirow[t]{4}{*}{ Model 3} & ESRD on dialysis vs CKD & -0.17 & 0.50 & 0.23 \\
\hline & HD or not & HD: 0.17 & 0.33 & 0.60 \\
\hline & & & & 0.87 (Q: 0.29, df: 2) \\
\hline & Methodological quality & 0.23 & 0.34 & 0.51 \\
\hline
\end{tabular}

ESRD, end-stage renal disease; CKD, chronic kidney disease; HD, hemodialysis; df, degrees of freedom.

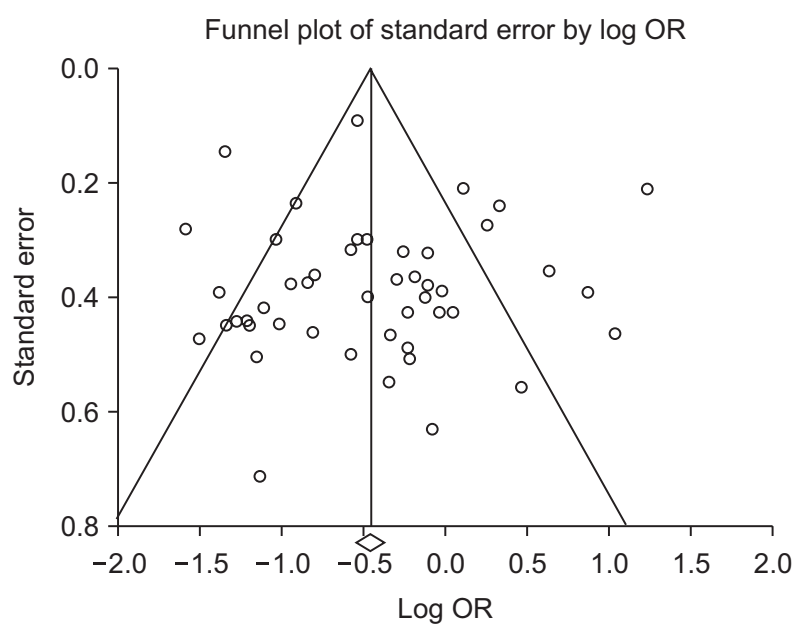

Fig. 4. Funnel plot of included studies. The line in the center is the natural logarithm of the pooled odds ratio (OR), and the two oblique lines are pseudo 95\% confidence limits.

which shows lower diagnostic value than the other tests. ${ }^{73}$ The diagnostic value of histology is higher than the other tests, but it is dependent on where the biopsies were conducted and how many specimens were obtained. The degree of atrophic gastritis or intestinal metaplasia is also important for obtaining biopsy tissue for histology, influencing the accurate determination of $H$. pylori infection status. ${ }^{3}$ In the previous meta-analysis, subgroup analysis revealed a trend of decreased risk of $H$. pylori infection in patients with CKD that was diagnosed with histology, excluding other diagnostic methods, and it had a marked decrease in heterogeneity between studies. ${ }^{7}$ This indicates that the diagnostic values of all currently available methods are not perfect and are only valid and accurate in certain situations. Taking into account all of the above considerations, only a single diagnostic method is insufficient, and combining diagnostic methods is expected to have a high diagnostic yield. Therefore, studies combining diagnostic methods were included in the low-risk group, and studies with single diagnostic method were included in the high-risk group of the incomplete outcome category of RoBANS in the current study.

Although the pathogenesis of a lower prevalence of $H$. pylori infection in patients with CKD is not completely understood, several hypotheses have been proposed to explain the mechanism. First, frequent use of antacids or antibiotics in patients 
with CKD might be associated with decreased prevalence. ${ }^{46}$ The subgroup analysis of the current study showed that the subgroup with a dialysis duration of more than 4 years showed a more intensified lower prevalence (OR, 0.34; 95\% CI, 0.27 to 0.43), and a previous meta-analysis also showed a consistent result, indicating frequent antacid or antibiotic consumption might be associated with this finding. ${ }^{6}$ Second, high blood urea nitrogen level was suspected as the cause of inhibited growth of H. pylori. ${ }^{45}$ However, this was not consistent in other studies. ${ }^{44,74}$ Lastly, increased inflammatory cytokines in patients with CKD leads to gastric mucosal damage, which in turn makes it difficult for $H$. pylori to survive. ${ }^{7,75}$

This meta-analysis included the largest number of articles identified by a comprehensive literature search, and potential confounding modifiers were searched within each study whenever possible. Sensitivity analyses, subgroup analyses, and meta-regression tests were performed to demonstrate robustness or to identify the reason of heterogeneity. Despite the strengths, several limitations were detected during the systematic review. First, only two studies presented adjusted outcomes. ${ }^{37,40}$ These two studies presented different associations between $H$. pylori infection and CKD (CKD vs control: OR, 0.64; 95\% CI, 0.51 to 0.81 in Chang et al. vs OR, 0.92; 95\% CI, 0.75 to 1.12 in Kong et al.). Considering the high methodological quality of Chang et al., the inverse association is consistent with the main result of current study, but more studies with adjusted variables are needed to explain this inconsistent result. Second, only casecontrol or cross-sectional studies were found during systematic review of this topic. Because the overall quality of the evidence is influenced by individual studies, future addition of high-quality studies would enhance the level of evidence. Third, it is not possible to determine the causality of the interaction-whether $H$. pylori influences the progression of kidney disease or CKD influences the $H$. pylori prevalence.

In conclusion, the results of this study suggest that there is a lower prevalence of $H$. pylori infection in patients with CKD.

\section{CONFLICTS OF INTEREST}

No potential conflict of interest relevant to this article was reported.

\section{ACKNOWLEDGEMENTS}

Funding for this research was provided by the Bio \& Medical Technology Development Program of the National Research Foundation (NRF) \& by the Korean government, Ministry of Science and ICT (MSIT) (grant number: NRF2017M3A9E8033253).

\section{AUTHOR CONTRIBUTIONS}

Conception and design of the study: C.S.B. Generation, col- lection, assembly, analysis and/or interpretation of data: S.P.S., C.S.B., J.J.L., G.H.B. Drafting or revision of the manuscript: S.P.S., C.S.B. Approval of the final version of the manuscript: C.S.B.

\section{ORCID}

Suk Pyo Shin https://orcid.org/0000-0002-5282-9174

Chang Seok Bang https://orcid.org/0000-0003-4908-5431

Jae Jun Lee https://orcid.org/0000-0002-5418-500X

Gwang Ho Baik https://orcid.org/0000-0003-1419-7484

\section{REFERENCES}

1. Schistosomes, liver flukes and Helicobacter pylori. IARC Working Group on the Evaluation of Carcinogenic Risks to Humans. Lyon, 7-14 June 1994. IARC Monogr Eval Carcinog Risks Hum $1994 ; 61: 1-241$

2. Bang CS, Kim YS, Park SH, et al. Additive effect of pronase on the eradication rate of first-line therapy for Helicobacter pylori infection. Gut Liver 2015;9:340-345.

3. Malfertheiner P, Megraud F, O'Morain CA, et al. Management of Helicobacter pylori infection: the Maastricht V/Florence Consensus Report. Gut 2017;66:6-30.

4. Wong F, Rayner-Hartley E, Byrne MF. Extraintestinal manifestations of Helicobacter pylori: a concise review. World J Gastroenterol 2014;20:11950-11961.

5. Goni E, Franceschi F. Helicobacter pylori and extragastric diseases. Helicobacter 2016;21 Suppl 1:45-48.

6. Gu M, Xiao S, Pan X, Zhang G. Helicobacter pylori infection in dialysis patients: a meta-analysis. Gastroenterol Res Pract 2013;2013:785892.

7. Wijarnpreecha K, Thongprayoon C, Nissaisorakarn P, et al. Association of Helicobacter pylori with chronic kidney diseases: a meta-analysis. Dig Dis Sci 2017;62:2045-2052.

8. Gunji T, Matsuhashi N, Sato H, et al. Helicobacter pylori infection significantly increases insulin resistance in the asymptomatic Japanese population. Helicobacter 2009;14:144-150.

9. Wijarnpreecha K, Thongprayoon C, Nissaisorakarn P, et al. Association between Helicobacter pylori and end-stage renal disease: a meta-analysis. World J Gastroenterol 2017;23:1497-1506.

10. Moher D, Liberati A, Tetzlaff J, Altman DG; PRISMA Group. Preferred reporting items for systematic reviews and meta-analyses: the PRISMA statement. Ann Intern Med 2009;151:264-269, W64.

11. Wang F, Liu J, Lv Z. Association of Helicobacter pylori infection with diabetes mellitus and diabetic nephropathy: a meta-analysis of 39 studies involving more than 20,000 participants. Scand J Infect Dis 2013;45:930-938.

12. Cheungpasitporn W, Thongprayoon C, Wijarnpreecha K, et al. Decline in prevalence and risk of Helicobacter pylori in kidney transplant recipients: a systematic review and meta-analysis. J Evid Based Med 2017;10:171-176.

13. Kim SY, Park JE, Lee YJ, et al. Testing a tool for assessing the risk 
of bias for nonrandomized studies showed moderate reliability and promising validity. J Clin Epidemiol 2013;66:408-414.

14. Higgins JP, Thompson SG. Quantifying heterogeneity in a metaanalysis. Stat Med 2002;21:1539-1558.

15. Higgins JP, Thompson SG, Deeks JJ, Altman DG. Measuring inconsistency in meta-analyses. BMJ 2003;327:557-560.

16. DerSimonian R, Laird N. Meta-analysis in clinical trials. Control Clin Trials 1986;7:177-188.

17. Duval S, Tweedie R. Trim and fill: a simple funnel-plot-based method of testing and adjusting for publication bias in metaanalysis. Biometrics 2000;56:455-463.

18. Sutton AJ, Abrams KR, Jones DR, Sheldon TA, Song F. Methods for meta-analysis in medical research. Chichester: Wiley; 2000.

19. Sterne JA, Egger M. Funnel plots for detecting bias in meta-analysis: guidelines on choice of axis. J Clin Epidemiol 2001;54:10461055.

20. Begg CB, Mazumdar M. Operating characteristics of a rank correlation test for publication bias. Biometrics 1994;50:1088-1101.

21. Egger M, Davey Smith G, Schneider M, Minder C. Bias in metaanalysis detected by a simple, graphical test. BMJ 1997;315:629634.

22. Karari EM, Lule GN, McLigeyo SO, Amayo EO. Endoscopic findings and the prevalence of Helicobacter pylori in chronic renal failure patients with dyspepsia. East Afr Med J 2000;77:406-409.

23. Tokushima $\mathrm{H}$. Role of Helicobacter pylori in gastro-duodenal mucosal lesions in patients with end-stage renal disease under dialysis treatment. Nihon Jinzo Gakkai Shi 1995;37:503-510.

24. Araki H, Miyazaki R, Matsuda T, Gejyo F, Koni I. Significance of serum pepsinogens and their relationship to Helicobacter pylori infection and histological gastritis in dialysis patients. Nephrol Dial Transplant 1999;14:2669-2675.

25. Tamura H, Tokushima H, Murakawa M, et al. Influences of Helicobacter pylori on serum pepsinogen concentrations in dialysis patients. Nephrol Dial Transplant 1999;14:113-117.

26. Misra V, Misra SP, Dwivedi M, et al. Decreased sensitivity of the ultrarapid urease test for diagnosing Helicobacter pylori in patients with chronic renal failure. Pathology 1999;31:44-46.

27. Kim DH, Jung HY, Yang SK, Hong WS, Min YI. Prevalence of Helicobacter pylori in patients with end stage renal disease. Korean J Gastrointest Endosc 2000;20:97-102.

28. Wang YL, Sheu BS, Huang JJ, Yang HB. Noninvasive stool antigen assay can effectively screen Helicobacter pylori Infection and assess success of eradication therapy in hemodialysis patients. Am J Kidney Dis 2001;38:98-103.

29. Tsukada K, Miyazaki T, Katoh H, et al. Seven-day triple therapy with omeprazole, amoxycillin and clarithromycin for Helicobacter pylori infection in haemodialysis patients. Scand J Gastroenterol 2002;37:1265-1268.

30. Tsukada K, Miyazaki T, Katoh H, et al. Helicobacter pylori infection in hemodialysis patients. Hepatogastroenterology 2003;50:2255-2258.

31. Misra V, Misra SP, Shukla SK, Jaiswal PK, Agarwal R, Tondon S.
Endoscopic and histological changes in upper gastrointestinal tract of patients with chronic renal failure. Indian J Pathol Microbiol 2004;47:170-173.

32. Nakajima F, Sakaguchi M, Oka H, et al. Prevalence of Helicobacter pylori antibodies in long-term dialysis patients. Nephrology (Carlton) 2004;9:73-76.

33. Moriyama T, Kaneko T, Fujii M, Tsubakihara Y, Kawano S, Imai E. High prevalence of Helicobacter pylori infection in Japanese patients with membranous nephropathy. Aliment Pharmacol Ther 2006;24(Suppl 4):189-193.

34. Abdulrahman IS, Al-Quorain AA. Prevalence of gastroesophageal reflux disease and its association with Helicobacter pylori infection in chronic renal failure patients and in renal transplant recipients. Saudi J Gastroenterol 2008;14:183-186.

35. Sugimoto M, Sakai K, Kita M, Imanishi J, Yamaoka Y. Prevalence of Helicobacter pylori infection in long-term hemodialysis patients. Kidney Int 2009;75:96-103.

36. Chang WC, Jo YI, Park HS, et al. Helicobacter pylori eradication with a 7-day low-dose triple therapy in hemodialysis patients. Clin Exp Nephrol 2010;14:469-473.

37. Chang SS, Hu HY. Lower Helicobacter pylori infection rate in chronic kidney disease and end-stage renal disease patients with peptic ulcer disease. J Chin Med Assoc 2014;77:354-359.

38. Bunchorntavakul C, Atsawarungruangkit A. Prevalence of asymptomatic gastroduodenal lesions and Helicobacter pylori infection in kidney transplant candidates. J Med Assoc Thai 2014;97 Suppl 11:S62-S68

39. Zhu TT, Wang L, Wang HL, He Y, Ma X, Fan JM. Helicobacter pylori participates in the pathogenesis of IgA nephropathy. Ren Fail 2016;38:1398-1404.

40. Kong X, Xu D, Li F, Ma X, Su H, Xu D. Association of H. pylori infection with chronic kidney disease among Chinese adults. Int Urol Nephrol 2017;49:845-850.

41. Offerhaus GJ, Kreuning J, Valentijn RM, et al. Campylobacter pylori: prevalence and significance in patients with chronic renal failure. Clin Nephrol 1989;32:239-241.

42. Shousha S, Arnaout AH, Abbas SH, Parkins RA. Antral Helicobacter pylori in patients with chronic renal failure. J Clin Pathol 1990;43:397-399.

43. Davenport A, Shallcross TM, Crabtree JE, Davison AM, Will EJ, Heatley RV. Prevalence of Helicobacter pylori in patients with end-stage renal failure and renal transplant recipients. Nephron 1991;59:597-601.

44. Loffeld RJ, Peltenburg HG, vd Oever H, Stobberingh E. Prevalence of Helicobacter pylori antibodies in patients on chronic intermittent haemodialysis. Nephron 1991;59:250-253.

45. Gladziwa U, Haase G, Handt S, et al. Prevalence of Helicobacter pylori in patients with chronic renal failure. Nephrol Dial Transplant 1993;8:301-306.

46. Jaspersen D, Fassbinder W, Heinkele P, et al. Significantly lower prevalence of Helicobacter pylori in uremic patients than in patients with normal renal function. J Gastroenterol 1995;30:585- 
588.

47. De Vecchi AF, Quatrini M, Boni F, et al. Epidemiology of Helicobacter pylori in dialysis patients. Perit Dial Int 1995;15:178-179.

48. Krawczyk W, Górna E, Suwała J, et al. Frequency of Helicobacter pylori infection in uremic hemodialyzed patients with antral gastritis. Nephron 1996;74:621-622.

49. Luzza F, Imeneo M, Maletta M, et al. Helicobacter pylori-specific IgG in chronic haemodialysis patients: relationship of hypergastrinaemia to positive serology. Nephrol Dial Transplant 1996;11:120124.

50. Fabrizi F, Martin P, Dixit V, et al. Epidemiology of Helicobacter pylori in chronic haemodialysis patients using the new RIBA $\mathrm{H}$. pylori SIA. Nephrol Dial Transplant 1999;14:1929-1933.

51. Závada J, Sulková S, Lukás M. Gastrointestinal hemorrhage and endoscopic findings in patients with chronic kidney failure. Vnitr Lek 2002;48:1011-1016.

52. Blusiewicz K, Rydzewska G, Rydzewski A. Gastric juice ammonia and urea concentrations and their relation to gastric mucosa injury in patients maintained on chronic hemodialysis. Rocz Akad Med Bialymst 2005;50:188-192.

53. Simunić M, Ljutić D, Mise S, Pesutić-Pisac V, Tonkić M, Hozo I. Helicobacter pylori eradication for the treatment of dyspeptic symptoms in chronic renal failure. Ann Saudi Med 2005;25:425427.

54. Nardone G, Rocco A, Fiorillo M, et al. Gastroduodenal lesions and Helicobacter pylori infection in dyspeptic patients with and without chronic renal failure. Helicobacter 2005;10:53-58.

55. Stolic RV, Jovanovic AN, Zivic ZP, et al. Influence of the level of renal insufficiency on endoscopic changes in the upper gastrointestinal tract. Am J Med Sci 2008;336:39-43.

56. Gioè FP, Cudia B, Romano G, et al. Role and clinical importance of Helicobacter pylori infection in hemodialysis patients. G Chir 2008;29:81-84.

57. Abu Farsakh NA, Roweily E, Rababaa M, Butchoun R. Brief report: evaluation of the upper gastrointestinal tract in uraemic patients undergoing haemodialysis. Nephrol Dial Transplant 1996;11:847850.

58. Seyrek N, Kocabas E, Hazar S, Paydas S, Aksaray N, Sagliker Y. Helicobacter pylori antibodies in patients on chronic hemodialysis. Nephron 1996;72:725-726.

59. Vardar R, Vardar E, Bozdağ H, Gürgen B, Postaci H, Özgenç O. Prevalence of Helicobacter pylori in patients with different renal function. Turk J Gastroenterol 1997;8:331-336.

60. Ozgür O, Boyacioğlu S, Ozdoğan M, Gür G, Telatar H, Haberal M. Helicobacter pylori infection in haemodialysis patients and renal transplant recipients. Nephrol Dial Transplant 1997;12:289-291.

61. Gür G, Boyacioglu S, Gül C, et al. Impact of Helicobacter pylori infection on serum gastrin in haemodialysis patients. Nephrol Dial
Transplant 1999;14:2688-2691.

62. Yildiz A, Beşişik F, Akkaya V, et al. Helicobacter pylori antibodies in hemodialysis patients and renal transplant recipients. Clin Transplant 1999;13(1 Pt 1):13-16.

63. Cekin AH, Boyacioglu S, Gursoy M, et al. Gastroesophageal reflux disease in chronic renal failure patients with upper GI symptoms: multivariate analysis of pathogenetic factors. Am J Gastroenterol 2002;97:1352-1356.

64. Al-Mueilo SH. Gastroduodenal lesions and Helicobacter pylori infection in hemodialysis patients. Saudi Med J 2004;25:1010-1014.

65. Khedmat H, Ahmadzad-Asl M, Amini M, et al. Gastro-duodenal lesions and Helicobacter pylori infection in uremic patients and renal transplant recipients. Transplant Proc 2007;39:1003-1007.

66. Asl MK, Nasri H. Prevalence of Helicobacter pylori infection in maintenance hemodialysis patients with non-ulcer dyspepsia. Saudi J Kidney Dis Transpl 2009;20:223-226.

67. Can Ö, Koç G, Ocak SB, et al. Gastrointestinal bleeding in patients with renal failure under hemodialysis treatment: a single-center experience. Int Urol Nephrol 2017;49:889-894.

68. Nieves M, Sulbarán J, Gaona C, Alvarado M, Salas Z, Serrano L. Gastroduodenitis and Helicobacter pylori in uremic patients. G E N 1992;46:113-120.

69. Olmos JA, Rosa Diez G, Higa R, et al. Helicobacter pylori seroprevalence in dialysis patients. Acta Gastroenterol Latinoam 2003;33:139-144.

70. Genta RM, Graham DY. Comparison of biopsy sites for the histopathologic diagnosis of Helicobacter pylori: a topographic study of $\mathrm{H}$. pylori density and distribution. Gastrointest Endosc 1994;40:342-345.

71. Braden B, Teuber G, Dietrich CF, Caspary WF, Lembcke B. Comparison of new faecal antigen test with (13)C-urea breath test for detecting Helicobacter pylori infection and monitoring eradication treatment: prospective clinical evaluation. BMJ 2000;320:148.

72. Gatta L, Vakil N, Ricci C, et al. Effect of proton pump inhibitors and antacid therapy on 13C urea breath tests and stool test for Helicobacter pylori infection. Am J Gastroenterol 2004;99:823829.

73. Loy CT, Irwig LM, Katelaris PH, Talley NJ. Do commercial serological kits for Helicobacter pylori infection differ in accuracy? A meta-analysis. Am J Gastroenterol 1996;91:1138-1144.

74. Nakajima F, Sakaguchi M, Amemoto K, et al. Helicobacter pylori in patients receiving long-term dialysis. Am J Nephrol 2002;22:468-472.

75. Hwang IR, Kodama T, Kikuchi S, et al. Effect of interleukin 1 polymorphisms on gastric mucosal interleukin 1beta production in Helicobacter pylori infection. Gastroenterology 2002;123:17931803. 